\title{
Suppression by Ghrelin of Porphyromonas gingivalis-Induced Constitutive Nitric Oxide Synthase S-Nitrosylation and Apoptosis in Salivary Gland Acinar Cells
}

\author{
Bronislaw L. Slomiany and Amalia Slomiany \\ Research Center, C875, University of Medicine and Dentistry of New Jersey Dental School, 110 Bergen Street, P.O. Box 1709, \\ Newark, NJ 07103-2400, USA \\ Correspondence should be addressed to Bronislaw L. Slomiany, slomiabr@umdnj.edu
}

Received 18 June 2010; Revised 20 July 2010; Accepted 4 August 2010

Academic Editor: Shoukat Dedhar

Copyright () 2010 B. L. Slomiany and A. Slomiany. This is an open access article distributed under the Creative Commons Attribution License, which permits unrestricted use, distribution, and reproduction in any medium, provided the original work is properly cited.

Oral mucosal inflammatory responses to periodontopathic bacterium, P. gingivalis, and its key virulence factor, LPS, are characterized by a massive rise in epithelial cell apoptosis and the disturbances in NO signaling pathways. Here, we report that the LPS-induced enhancement in rat sublingual salivary gland acinar cell apoptosis and NO generation was associated with the suppression in constitutive nitric oxide synthase (cNOS) activity and a marked increase in the activity of inducible nitric oxide synthase (iNOS). We demonstrate that the detrimental effect of the LPS on cNOS was manifested by the enzyme protein Snitrosylation, that was susceptible to inhibition by iNOS inhibitor, $1400 \mathrm{~W}$. Further, we show that a peptide hormone, ghrelin, countered the LPS-induced changes in apoptosis and cNOS activity. This effect of ghrelin was reflected in the decrease in cNOS $S$-nitrosylation and the increase in phosphorylation. Our findings imply that $P$. gingivalis-induced disturbances in the acinar cell NO signaling pathways result from upregulation in iNOS-derived NO that causes cNOS S-nitrosylation that interferes with its activation through phosphorylation. We also show that ghrelin protection against $P$. gingivalis-induced disturbances involves $\mathrm{cNOS}$ activation associated with a decrease in its S-nitrosylation and the increase in phosphorylation.

\section{Introduction}

Nitric oxide is a multifunctional, short-lived signaling molecule that plays an important role in a variety of regulatory pathways that are of significance to cellular survival, integrity maintenance, and the modulation of inflammatory responses to bacterial infection [1-3]. The physiological and pathophysiological implications of $\mathrm{NO}$ depend on its local concentration, the type of NOS isozyme involved in NO generation, substrate availability, and the enzyme compartmentalization with respect to protein target $[1,3]$. Indeed, a low level of NO generated by membraneassociated cNOS appears to access a pool of substrates that are of importance to maintenance of normal physiological functions, including the regulation of apoptogenic signal propagation [3-5]. In contrast, a high level of NO generated by more distant cytosolic iNOS in response to proinflam- matory cytokines or bacterial LPS, is of importance to host defense, but its sustained production is associated with the induction of apoptosis $[1,5,6]$. Therefore, the disturbances in cNOS activation associated with bacterial colonization may be a major factor defining the extent of inflammatory involvement.

Studies indicate that cNOS activity is regulated by a complex set of pre- and posttranslational modifications that affect the dynamic of its subcellular targeting and the activity by exposing the enzyme to fatty acid modification through $\mathrm{N}$-myristoylation and thiopalmitoylation, interaction with regulatory cofactors, and the protein phosphorylation with the involvement of Src/Akt pathway [7-10]. Furthermore, there are recent reports that cNOS enzyme protein S-nitrosylation at the critical zinctetrathiolate cysteine residues leads to a transient inhibition of cNOS activity $[11,12]$. It is also becoming increasingly 
apparent that, like posttranslational modification through phosphorylation, the protein S-nitrosylation is a targeted and reversible physiologically important posttranslational modification that regulates a large variety of cellular signaling events, including transmittance fidelity of NO signals $[3-6,11]$. The S-nitrosylation of mitochondrial protein thiols is known to block cell death after glutathione depletion, and contributes to redox regulatory activity and antiapoptotic function of thioredoxin $[3,13]$. More importantly, the cNOS-generated NO has been implicated in the inhibition of apoptogenic signal through Snitrosylation of the key executioner caspase, caspase-3 [14$16]$.

Recent advances in identifying the salivary constituents that are capable of influencing the extent of oral mucosal inflammatory responses have brought to focus the importance of a peptide hormone, ghrelin [17]. Emerging evidence indicates that this 28 -amino acid peptide, initially isolated from the stomach [18], and more recently identified in saliva and the acinar cells of salivary glands [17], is a principal modulator of the local inflammatory responses to bacterial infection through the regulation of NOS system responsible for NO production $[19,20]$. Moreover, we have shown recently that the countering effect of ghrelin on $P$. gingivalis LPS-induced salivary gland cell apoptosis was reflected in the increase in cNOS activity [16].

As the oral mucosal inflammatory responses to periodontopathic bacterium, $P$. gingivalis, are characterized by the enhanced epithelial cell apoptosis and the disturbances in NO signaling pathways $[21,22]$, in this study we investigated further the nature of the impairment in NOS generating system induced in sublingual salivary gland acinar cells by the LPS of $P$. gingivalis. Our data revealed that the disturbances in the acinar cell $\mathrm{NO}$ generation system caused by the LPS results from iNOS-induced suppression of cNOS activation through S-nitrosylation, and that the countering effect of ghrelin was reflected in a marked decrease in cNOS S-nitrosylation and the increase in the enzyme protein phosphorylation.

\section{Materials and Methods}

2.1. Salivary Gland Cell Incubation. The acinar cells of sublingual salivary gland, collected from freshly dissected rat salivary glands, were suspended in five volumes of ice-cold Dulbecco's modified (Gibco) Eagle's minimal essential medium (DMEM), supplemented with fungizone $(50 \mu \mathrm{g} / \mathrm{mL})$, penicillin $(50 \mathrm{U} / \mathrm{mL})$, streptomycin $(50 \mu \mathrm{g} / \mathrm{mL})$, and $10 \%$ fetal calf serum, and gently dispersed by trituration with a syringe, and settled by centrifugation [22]. Following rinsing, the cells were resuspended in the medium to a concentration of $2 \times 10^{7}$ cell $/ \mathrm{mL}$, transferred in $1 \mathrm{~mL}$ aliquots to DMEM in culture dishes and incubated under $95 \% \quad \mathrm{O}_{2}-5 \% \quad \mathrm{CO}_{2}$ atmosphere at $37^{\circ} \mathrm{C}$ for $16 \mathrm{~h}$ in the presence of $0-200 \mathrm{ng} / \mathrm{mL}$ of $P$. gingivalis LPS [23]. In the experiments evaluating the effect of ghrelin (rat, Sigma), cNOS inhibitor, L-NAME, iNOS inhibitor, $1400 \mathrm{~W}$, Src inhibitor, PP2, Akt inhibitor, SH-5 (Calbiochem), and ascorbate (Sigma), the cells were first preincubated for 30 minutes with the indicated dose of the agent or vehicle before the addition of the LPS. The viability of cell preparations before and during the experimentation, assessed by Trypan blue dye exclusion assay [23], was greater than $98 \%$.

2.2. Porphyromonas Gingivalis Lipopolysaccharide. P. gingivalis used for LPS preparation was cultured from clinical isolates obtained from ATCC No. 33277 [23]. The bacterium was homogenized with liquid phenol-chloroform-petroleum ether, centrifuged, and the LPS contained in the supernatant was precipitated with water, washed with $80 \%$ phenol solution and dried with ether. The dry residue was dissolved in a small volume of water at $45^{\circ} \mathrm{C}$, centrifuged at $100,000 \times \mathrm{g}$ for 4 hours, and the resulting LPS sediment subjected to lyophilization. The preparation was essentially free of nucleic acid and its protein content was less than $0.2 \%$.

\subsection{Apoptosis and NO Quantification. Quantitative mea-} surement of the acinar cell apoptosis was carried out with a sandwich enzyme immunoassay (Boehringer Mannheim) directed against cytoplasmic histone-associated DNA fragments [22]. The cells from the control and various experimental conditions were settled by centrifugation, rinsed with phosphate-buffered saline, and incubated in the lysis buffer in accordance with the manufacturer's instructions. The lysates were centrifuged at $20,000 \mathrm{~g}$ for 10 minutes, and the diluted $(1: 100)$ supernatant containing the cytoplasmic histone-associated DNA fragments were reacted in the microtiter wells with immobilized antihistone antibody. After washing, the retained complex was reacted with antiDNA peroxidase, and the immunocomplex-bound peroxidase probed with ABTS reagent for spectrophotometric quantification [22]. To assess NO production in the acinar cells, we measured the stable NO metabolite, nitrite, accumulation in the culture medium using Griess reaction [24]. A $100 \mu \mathrm{l}$ of spent culture medium was incubated for 10 minutes with $0.1 \mathrm{~mL}$ of Griess reagent (Sigma) and the absorbance was measured at $570 \mathrm{~nm}$.

2.4. cNOS and iNOS Activity Assay. Nitric oxide synthase activities of cNOS and iNOS enzymes in the acinar cells was measured by monitoring the conversion of $\mathrm{L}-\left[{ }^{3} \mathrm{H}\right]$ arginine to L- $\left[{ }^{3} \mathrm{H}\right]$ citrulline using NOS-detect kit (Stratagene). The cells from the control and experimental treatments were homogenized in a sample buffer containing either $10 \mathrm{mM}$ EDTA (for $\mathrm{Ca}^{2+}$-independent iNOS) or $6 \mathrm{mM} \mathrm{CaCl}_{2}$ (for $\mathrm{Ca}^{2+}$-dependent cNOS), and centrifuged [22]. The aliquots of the resulting supernatant were incubated for 30 minutes at $25^{\circ} \mathrm{C}$ in the presence of $50 \mu \mathrm{Ci} / \mathrm{mL}$ of $\mathrm{L}-\left[{ }^{3} \mathrm{H}\right]$ arginine, $10 \mathrm{mM}$ NAPDH, $5 \mu \mathrm{M}$ tetrahydrobiopterin, and $50 \mathrm{mM}$ Tis$\mathrm{HCl}$ buffer, $\mathrm{pH} 7.4$, in a final volume of $250 \mu \mathrm{l}$. Following addition of stop buffer and Dowex-50 W $\left(\mathrm{Na}^{+}\right)$resin, the mixtures were transferred to spin cups, centrifuged and the formed L- $\left[{ }^{3} \mathrm{H}\right]$ citrulline contained in the flow through was quantified by scintillation counting. 
2.5. cNOS S-Nitrosylation. Detection of cNOS Snitrosylation was carried out employing a biotin switch procedure for protein S-nitrosylation $[25,26]$. The acinar cells were treated with iNOS inhibitor, $1400 \mathrm{~W}(30 \mu \mathrm{M})$ or ghrelin $(0.6 \mu \mathrm{g} / \mathrm{mL})$ or Src inhibitor, PP2 $(20 \mu \mathrm{M})+$ ghrelin and incubated for 16 hours in the presence of $100 \mathrm{ng} / \mathrm{mL}$ of P. gingivalis LPS. Following centrifugation at $500 \times \mathrm{g}$ for 5 minutes, the recovered cells were lysed in $0.2 \mathrm{~mL}$ of HEN lysis buffer (250 mM HEPES, 1 mM EDTA, 0.1 mM neocuproine, $\mathrm{pH}$ 7.7), and the unnitrosylated thiol groups were blocked with S-methyl methanethiosulfonate reagent [26]. The proteins were precipitated with acetone, resuspended in $0.2 \mathrm{~mL}$ of HEN buffer containing $1 \%$ SDS, and subjected to targeted nitrothiol group reduction with sodium ascorbate $(100 \mathrm{mM})$. The free thiols were then labeled with biotin and the biotinylated proteins were recovered on streptavidin beads. The formed streptavidin bead-protein complex was washed with neutralization buffer, and the bound proteins were dissociated from streptavidin beads with $50 \mu \mathrm{l}$ of elution buffer (20 mM HEPES, $100 \mathrm{mM} \mathrm{NaCl}, 1 \mathrm{mM}$ EDTA, pH 7.7) containing 1\% 2-mercaptoethanol [26]. The obtained proteins were then analyzed by Western blotting.

2.6. Western Blot Analysis. The acinar cells from the control and experimental treatments were collected by centrifugation and resuspended for 30 minutes in ice-cold lysis buffer [10]. Following brief sonication, the lysates were centrifuged at $12,000 \mathrm{~g}$ for 10 minutes, and the supernatants were subjected to protein determination using BCA protein assay kit (Pierce). The samples, including those subjected to biotin switch procedure, were then resuspended in loading buffer, boiled for 5 minutes, and subjected to SDS-PAGE using $50 \mu \mathrm{g}$ protein/lane. The separated proteins were transferred onto nitrocellulose membranes, blocked with 5\% skim milk, and probed with the antibody against phosphorylated protein at $4^{\circ} \mathrm{C}$ for 16 hours. After 1 hour incubation with the horseradish peroxidase-conjugated secondary antibody, the phosphorylated proteins were revealed using an enhanced chemiluminescence. Membranes were stripped by incubation in $1 \mathrm{M}$ Tris- $\mathrm{HCl}(\mathrm{pH} 6.8), 10 \%$ SDS, and $10 \mathrm{mM}$ dithiotreitol for 30 minutes at $55^{\circ} \mathrm{C}$, and reprobed with antibody against total cNOS. Immunoblotting was performed using specific antibodies directed against cNOS and phospho-cNOS (Ser ${ }^{1179}$ ) (Calbiochem).

2.7. Data Analysis. All experiments were carried out using duplicate sampling, and the results are expressed as means \pm SD. Analysis of variance (ANOVA) followed by nonparametric Kruskal-Wallis test was used to determine significance and the significance level was set at $P<.05$.

\section{Results}

To examine the role of NO generated by cNOS and iNOS isozyme systems in propagation of apoptogenic processes induced by periodontopathic bacterium, $P$. gingivalis, we employed rat sublingual salivary gland acinar cells exposed to the bacterium key virulence factor, LPS. Using apoptotic

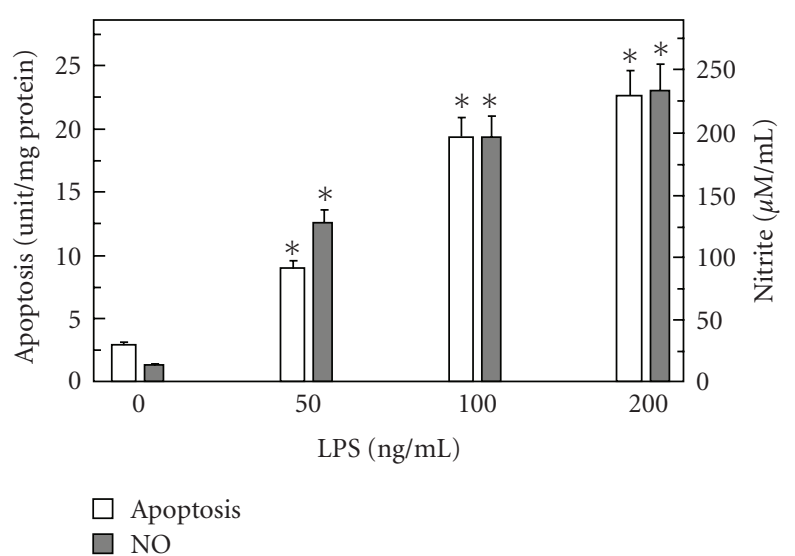

FIGURE 1: Effect of $P$. gingivalis LPS on rat sublingual salivary gland acinar cell apoptosis and nitrite production. The cells were treated with the indicated concentrations of the LPS and incubated for 16 hours. Values represent the means \pm SD of five experiments. ${ }^{*} P<$ .05 compared with that of control (LPS -0$)$.

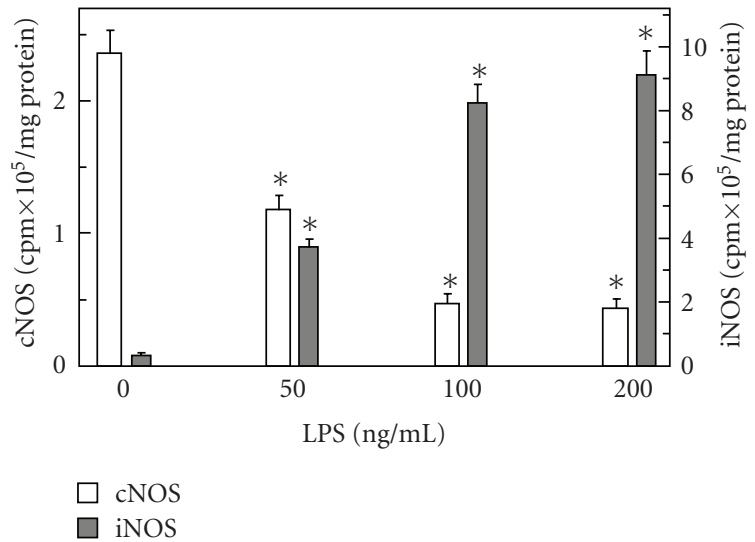

Figure 2: Effect of $P$. gingivalis LPS on the expression of inducible (iNOS) and constitutive (cNOS) nitric oxide synthase activities in rat sublingual salivary gland acinar cells. The cells were treated with the indicated concentrations of the LPS and incubated for 16 hours. Values represent the means $\pm \mathrm{SD}$ of five experiments. ${ }^{*} P<.05$ compared with that of control (LPS - 0).

DNA fragmentation assay in conjunction with the measurements of NO, we demonstrated that $P$. gingivalis LPS caused a dose-dependent increase in the acinar cell apoptosis and NO production, which at $100 \mathrm{ng} / \mathrm{mL}$ LPS reached respective values of 6.7- and 15.1-fold over that of controls (Figure 1). We also established that the effect of the LPS at $100 \mathrm{ng} / \mathrm{mL}$ on NO production was reflected in a 26.4 -fold increase in the acinar cell iNOS activity, while the cNOS activity showed a 5.2-fold decrease (Figure 2).

Moreover, we found that preincubation with ghrelin led to a concentration-dependent reversal in the LPS-induced changes, which at $0.6 \mu \mathrm{g} / \mathrm{mL}$ resulted in an $80.6 \%$ drop in apoptosis as well as a $94.3 \%$ decrease in the LPS-induced acinar cell iNOS activity (Figure 3 ). However, the activity of cNOS in the presence of $0.6 \mu \mathrm{g} / \mathrm{mL}$ ghrelin showed an $80.4 \%$ increase over that of the LPS (Figure 4). 


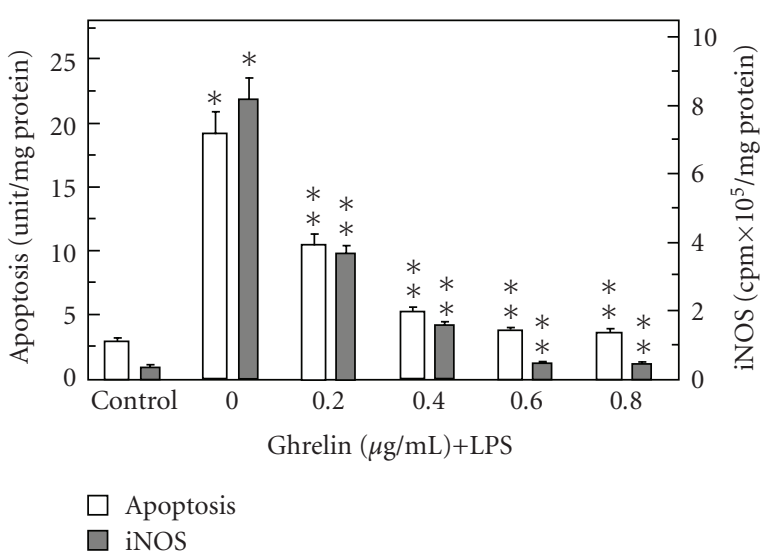

Figure 3: Effect of ghrelin on $P$. gingivalis LPS-induced sublingual salivary gland acinar cell apoptosis and iNOS activity. The cells, preincubated with the indicated concentrations of ghrelin, were treated with the LPS at $100 \mathrm{ng} / \mathrm{mL}$ and incubated for 16 hours. Values represent the means $\pm \mathrm{SD}$ of five experiments. ${ }^{*} P<.05$ compared with that of control. ${ }^{* *} P<.05$ compared with that of LPS alone.

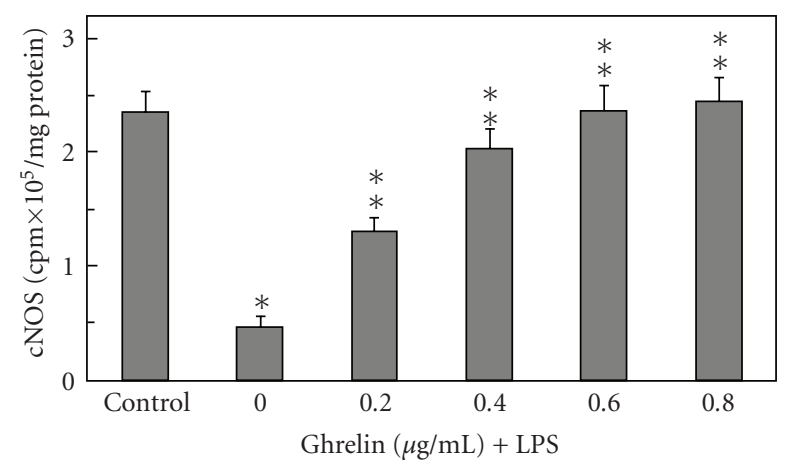

FIgURe 4: Effect of ghrelin on P. gingivalis LPS-induced expression of cNOS activity in sublingual salivary gland acinar cells. The cells, preincubated with the indicated concentrations of ghrelin, were treated with the LPS at $100 \mathrm{ng} / \mathrm{mL}$ and incubated for 16 hours. Values represent the means $\pm \mathrm{SD}$ of five experiments. ${ }^{*} P<.05$ compared with that of control. ${ }^{* *} P<.05$ compared with that of LPS alone.

To gain further insight into the relationship between ghrelin-induced upregulation in cNOS activity and the suppression of $P$. gingivalis LPS-induced acinar cell apoptosis, we first focused on examining the effect ghrelin on the events associated with cNOS activation. As cNOS is known to a rapid posttranslational activation through its protein phosphorylation at $\operatorname{Ser}^{1177}$ (human) or $\operatorname{Ser}^{1179}$ (rat) with the involvement of Src/Akt pathway $[9,10,20,27]$, the acinar cells prior to incubation with ghrelin were pretreated with Src kinase inhibitor, PP2, or Akt inhibitor, Sh-5, or cNOS inhibitor, L-NAME, and assayed for apoptosis. As shown in Figure 5, all three agents significantly inhibited the countering effect of ghrelin on the LPS-induced apoptosis.

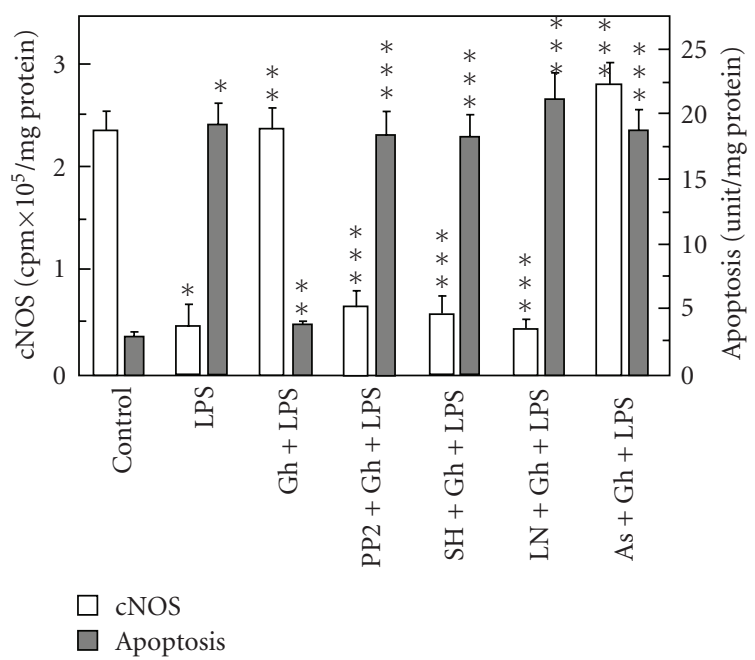

Figure 5: Effect of cNOS inhibitors on the ghrelin (Gh)-induced changes in apoptosis and cNOS activity in the acinar cell exposed to $P$. gingivalis LPS. The cells, preincubated with $20 \mu \mathrm{M}$ PP2, $30 \mu \mathrm{M}$ SH-5 (SH), $300 \mu \mathrm{M}$ ascorbate (As), or $400 \mu \mathrm{M}$ L-NAME (LN), were treated with Gh (at $0.6 \mu \mathrm{g} / \mathrm{mL}$ ) and incubated for 16 hours in the presence of $100 \mathrm{ng} / \mathrm{mL}$ LPS. Values represent the means $\pm \mathrm{SD}$ of five experiments. ${ }^{*} P<.05$ compared with that of control. ${ }^{* *} P<.05$ compared with that of LPS alone. ${ }^{* * *} P<.05$ compared with that of Gh + LPS.

Moreover, the effects of PP2 and SH-5, like that of LNAME, were reflected in the inhibition of ghrelin-induced cNOS activity (Figure 5). However, preincubation with nitrosothiols reducing agent, ascorbate $[25,26]$, produced amplification in the effect of ghrelin on cNOS activity (Figure 5), thus suggesting that in addition to Src/Akt kinase-mediated activation through phosphorylation, the activity of cNOS may be also dependent upon its protein S-nitrosylation.

To assess further the course of events resulting in the suppression of cNOS activity by $P$. gingivalis LPS as well as to shed a light on the mechanism of ghrelin countering effect, the acinar cells were exposed to incubation with the LPS and ghrelin +LPS, and the lysates subjected to biotin switch procedure were probed with antibodies directed against phospho-cNOS and total cNOS. We observed that the acinar cells exposed to the LPS alone showed a marked increase in cNOS protein S-nitrosylation, while the effect of ghrelin was reflected in the loss in cNOS S-nitrosylation and the increase in its protein phosphorylation (Figure 6). Furthermore, the suppression of ghrelin effect on cNOS activity by Src kinase inhibitor, PP2 (Figure 5), was manifested in the inhibition of cNOS phosphorylation (Figure 6).

To explore the dependence of cNOS S-nitrosylation on $P$. gingivalis LPS-induced iNOS activity, we pretreated the acinar cells with iNOS inhibitor, $1400 \mathrm{~W}$, and following incubation with the LPS the lysates were subjected to the biotin switch procedure, and examined for cNOS S-nitrosylation. Western blot analysis revealed that the blockage of iNOS activity lead to a substantial decrease in the LPS-induced cNOS S-nitrosylation (Figure 7). 

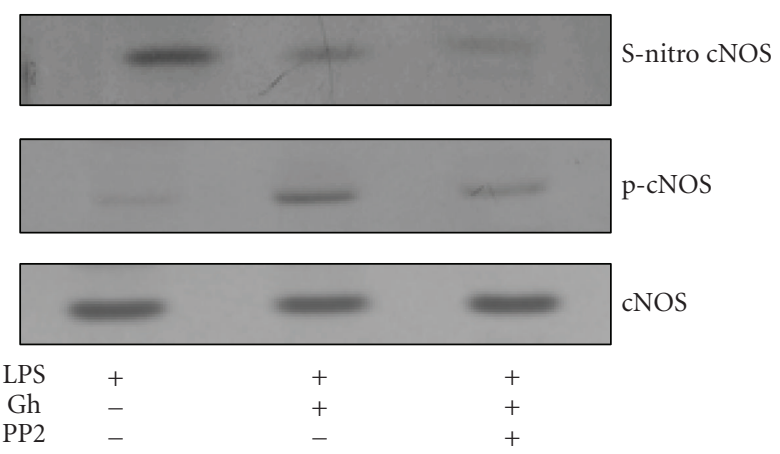

FIGURE 6: Effect of ghrelin (Gh) on $P$. gingivalis LPS-induced cNOS S-nitrosylation in sublingual salivary gland acinar cells. The cells were treated with $\mathrm{Gh}(0.6 \mu \mathrm{g} / \mathrm{mL})$ or PP2 $(20 \mu \mathrm{M})+\mathrm{Gh}$ and incubated for 16 hours in the presence of $100 \mathrm{ng} / \mathrm{ml}$ LPS. A portion of the cell lysates was processed by biotin switch method for protein S-nitrosylation and, along with the remainder of the lysates, resolved on SDS-PAGE, transferred to nitrocellulose and probed with phosphorylation-specific cNOS (pcNOS) antibody, and after stripping reprobed with anti-cNOS antibody. The immunoblots shown are representative of three experiments.

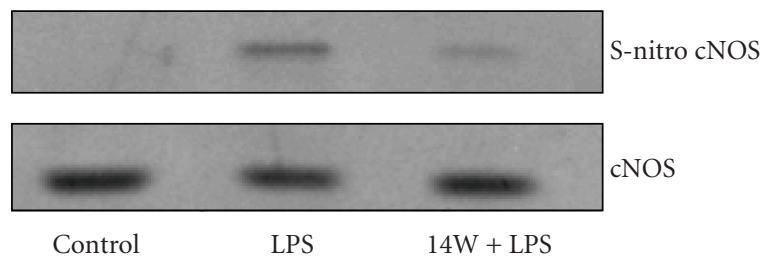

FIgUre 7: Effect of iNOS inhibitor, $1400 \mathrm{~W}(14 \mathrm{~W})$ on $P$. gingivalis LPS-induced cNOS S-nitrosylation. The acinar cells were treated with the LPS $(100 \mathrm{ng} / \mathrm{mL})$ or $14 \mathrm{~W}(30 \mu \mathrm{M})+$ LPS and incubated for 16 hours in the presence of $100 \mathrm{ng} / \mathrm{mL}$ LPS. A portion of the cell lysates was processed by biotin switch procedure for protein Snitrosylation and, along with the reminder of the lysates, subjected to SDS-PAGE, transferred to nitrocellulose and probed with anticNOS antibody. The immunoblots shown are representative of three experiments.

\section{Discussion}

A Gram-negative bacterium, $P$. gingivalis, found in periodontal packets of patients with persistent oral mucosal inflammations, is recognized as a main culprit in the development of periodontal disease that is the major cause of adult tooth loss $[28,29]$. The oral mucosal responses to $P$. gingivalis and its key virulence factor, cell wall LPS, are manifested by a massive rise in epithelial cell apoptosis, increase in proinflammatory cytokine production, and the disturbances in NO signaling pathways [21-23]. Therefore, in this study we investigated the nature of the impairment in NOS generating system induced in sublingual salivary gland acinar cells by $P$. gingivalis LPS.

Our findings revealed that the LPS-induced enhancement in the acinar cell apoptosis and the disturbances in $\mathrm{NO}$ were associated with the suppression of in cNOS activity and a marked upregulation in the activity of iNOS. Further, preincubation with a peptide hormone, ghrelin, recently identified in saliva and recognized for its modulatory effect on the inflammatory responses to bacterial infection [16, 17, 19], elicited a decrease in the LPS-induced apoptosis and iNOS. Moreover, ghrelin countered the LPS-induced suppression in the activity of cNOS. These results are thus in keeping with the conclusions of earlier studies demonstrating that the proapoptotic effects of $P$. gingivalis LPS are directly linked to the events of associated with iNOS induction and caspase 3 activation $[16,22]$. The fact that the LPS-induced proapoptotic events were accompanied by a marked decrease in cNOS activity, while the countering effect of ghrelin was reflected in a decrease in iNOS and upregulation in cNOS, attests to the modulatory role of cNOS-derived NO on the apoptogenic signal propagation. The accumulating evidence, furthermore, suggests that ghrelin plays a major role in the regulation of local inflammatory responses through upregulation in cNOS-induced NO production $[19,20,30]$ Moreover, the cNOS-derived NO has been implicated in the inhibition of apoptogenic signal through S-nitrosylation of the key executioner caspase, caspase-3 $[3,14,16]$, and there are recent reports as to the regulation of cNOS activity through the enzyme protein S-nitrosylation $[11,12]$.

Indeed, the available literature data indicate that the activity of cNOS is regulated by a complex set of co- and posttranslational modifications, including fatty acid addition through $\mathrm{N}$-myristoylation and thiopalmitoylation, interaction with regulatory cofactors, and the protein phosphorylation [7-10, 27]. Hence, to gain an insight into the mechanism of $P$. gingivalis LPS-induced changes in cNOS activity and the effect of ghrelin, we focused further on examining the events associated with cNOS activation. We found that, in keeping with the documented involvement of Src/Akt pathway in cNOS posttranslational activation through phosphorylation at $\operatorname{Ser}^{1179}[9,10,20,27]$, the countering effect of ghrelin on the LPS-induced changes in cNOS activity as well as apoptosis were subject to suppression by Src kinase inhibitor, PP2, Akt inhibitor, SH-5, and cNOS inhibitor, L-NAME. However, preincubation with nitrosothiols reducing agent, ascorbate $[25,26]$, resulted in amplification of the effect of ghrelin on cNOS activity. Together, these data suggest that ghrelin countering effect on the LPS-induced proapoptotic events occurs with the involvement of Src/Akt kinasemediated cNOS activation through phosphorylation, that appears to be dependent upon the extent of cNOS protein S-nitrosylation. Our results furthermore, are supported by the recent reports demonstrating that ascorbate treatment both increases cNOS activity and reduces the enzyme protein S-nitrosylation $[11,12]$. Indeed, the growing evidence suggests that like posttranslational modification through phosphorylation, the protein S-nitrosylation is a targeted and reversible physiologically important posttranslational event that regulates protein activity during cell signaling [3$6,11,16,30]$.

Our assertion that $P$. gingivalis LPS-induced Snitrosylation of the acinar cell cNOS interferes with the enzyme activation through its protein phosphorylation is supported further by the results biotin switch assay. We found that the acinar cells exposed to incubation 
with the LPS alone showed a marked increase in cNOS S-nitrosylation. The countering effect of ghrelin on the LPS-induced suppression in cNOS activity was reflected in the loss in S-nitrosylation and the increase in the enzyme protein phosphorylation, while the suppression of ghrelin by Src kinase inhibitor, PP2, was manifested in the inhibition of cNOS phosphorylation. Interestingly, recent data indicate that stimulus-activated (VEGF) targeting of cNOS to cellular membrane is associated with both an increase in enzyme protein phosphorylation as well as a decrease in its S-nitrosylation $[11,12]$.

Finally, our data also revealed the dependence of cNOS Snitrosylation on $P$. gingivalis LPS-induced iNOS activity. We observed that suppression of the LPS-induced iNOS activity with a specific inhibitor, $1400 \mathrm{~W}$, led to a substantial decrease in cNOS S-nitrosylation. These results are thus indicative of the involvement of iNOS-derived NO in the suppression of cNOS activity through S-nitrosylation.

In conclusion, the data provided in our study suggest that $P$. gingivalis LPS-induced disturbances in the acinar cell NO signaling pathways result from upregulation in iNOS that leads to the induction in NO generation and cNOS Snitrosylation that interferes with its activation. Furthermore, our findings demonstrate that following ghrelin stimulation, cNOS appears to undergo a rapid activation associated with a marked decrease in its S-nitrosylation and the increase in the protein phosphorylation.

\section{References}

[1] R. Korhonen, A. Lahti, H. Kankaanranta, and E. Moilanen, "Nitric oxide production and signaling in inflammation," Current Drug Targets: Inflammation \& Allergy, vol. 4, no. 4, pp. 471-479, 2005.

[2] S. Cuzzocrea and D. Salvemini, "Molecular mechanisms involved in the reciprocal regulation of cyclooxygenase and nitric oxide synthase enzymes," Kidney International, vol. 71, no. 4, pp. 290-297, 2007.

[3] J. Sun, C. Steenbergen, and E. Murphy, "S-nitrosylation: NOrelated redox signaling to protect against oxidative stress," Antioxidants and Redox Signaling, vol. 8, no. 9-10, pp. 16931705, 2006.

[4] Y.-M. Kim, R. V. Talanian, and T. R. Billiar, "Nitric oxide inhibits apoptosis by preventing increases in caspase-3-like activity via two distinct mechanisms," Journal of Biological Chemistry, vol. 272, no. 49, pp. 31138-31148, 1997.

[5] P. Chanvorachote, U. Nimmannit, L. Wang et al., "Nitric oxide negatively regulates Fas CD95-induced apoptosis through inhibition of ubiquitin-proteasome-mediated degradation of FLICE inhibitory protein," Journal of Biological Chemistry, vol. 280, no. 51, pp. 42044-42050, 2005.

[6] M.-C. Maa, Y. C. Miao, Y.-J. Chen et al., "Requirement of inducible nitric-oxide synthase in lipopolysaccharidemediated Src induction and macrophage migration," Journal of Biological Chemistry, vol. 283, no. 46, pp. 31408-31416, 2008.

[7] D. Fulton, J.-P. Gratton, and W. C. Sessa, "Post-translational control of endothelial nitric oxide synthase: why isn't calcium/calmodulin enough?" Journal of Pharmacology and Experimental Therapeutics, vol. 299, no. 3, pp. 818-824, 2001.
[8] E. Gonzalez, R. Kou, A. J. Lin, D. E. Golan, and T. Michel, "Subcellular targeting and agonist-induced site-specific phosphorylation of endothelial nitric-oxide synthase," Journal of Biological Chemistry, vol. 277, no. 42, pp. 39554-39560, 2002.

[9] M. P. Haynes, L. Li, D. Sinha et al., "Src kinase mediates phosphatidylinositol 3-kinase/Akt-dependent rapid endothelial nitric-oxide synthase activation by estrogen," Journal of Biological Chemistry, vol. 278, no. 4, pp. 2118-2123, 2003.

[10] B. L. Slomiany and A. Slomiany, "Leptin protection of salivary gland acinar cells against ethanol cytotoxicity involves Src kinase-mediated parallel activation of prostaglandin and constitutive nitric oxide synthase pathways," Inflammopharmacology, vol. 16, no. 2, pp. 76-82, 2008.

[11] P. A. Erwin, A. J. Lin, D. E. Golan, and T. Michel, "Receptorregulated dynamic S-nitrosylation of endothelial nitric-oxide synthase in vascular endothelial cells," Journal of Biological Chemistry, vol. 280, no. 20, pp. 19888-19894, 2005.

[12] P. A. Erwin, D. A. Mitchell, J. Sartoretto, M. A. Marletta, and T. Michel, "Subcellular targeting and differential S-nitrosylation of endothelial nitric-oxide synthase," Journal of Biological Chemistry, vol. 281, no. 1, pp. 151-157, 2006.

[13] M. Whiteman, Y. L. Chua, D. Zhang, W. Duan, Y.-C. Liou, and J. S. Armstrong, "Nitric oxide protects against mitochondrial permeabilization induced by glutathione depletion: role of Snitrosylation?" Biochemical and Biophysical Research Communications, vol. 339, no. 1, pp. 255-262, 2006.

[14] J. B. Mannick, "Regulation of apoptosis by protein Snitrosylation,” Amino Acids, vol. 32, no. 4, pp. 523-526, 2007.

[15] Y. Maejima, S. Adachi, K. Morikawa, H. Ito, and M. Isobe, "Nitric oxide inhibits myocardial apoptosis by preventing caspase-3 activity via S-nitrosylation," Journal of Molecular and Cellular Cardiology, vol. 38, no. 1, pp. 163-174, 2005.

[16] B. L. Slomiany and A. Slomiany, "Constitutive nitric oxide synthase-mediated caspase-3 S-nitrosylation in ghrelin protection against Porphyromonas gingivalis-induced salivary gland acinar cell apoptosis," Inflammopharmacology, vol. 18, pp. 119-125, 2010.

[17] M. Gröschl, H. G. Topf, J. Bohlender et al., "Identification of ghrelin in human saliva: production by the salivary glands and potential role in proliferation of oral keratinocytes," Clinical Chemistry, vol. 51, no. 6, pp. 997-1006, 2005.

[18] M. Kojima, H. Hosoda, Y. Date, M. Nakazato, H. Matsuo, and K. Kangawa, "Ghrelin is a growth-hormone-releasing acylated peptide from stomach," Nature, vol. 402, no. 6762, pp. 656660, 1999.

[19] T. Waseem, M. Duxbury, H. Ito, S. W. Ashley, and M. K. Robinson, "Exogenous ghrelin modulates release of proinflammatory and anti-inflammatory cytokines in LPSstimulated macrophages through distinct signaling pathways," Surgery, vol. 143, no. 3, pp. 334-342, 2008.

[20] X. Xu, S. J. Bong, H. H. Chang, and Z.-G. Jin, "Molecular mechanisms of ghrelin-mediated endothelial nitric oxide synthase activation," Endocrinology, vol. 149, no. 8, pp. 41834192, 2008.

[21] P.-L. Wang and K. Ohura, "Porphyromonas gingivalis lipopolysaccharide signaling in gingival fibroblasts- CD14 and Toll-like receptors," Critical Reviews in Oral Biology and Medicine, vol. 13, no. 2, pp. 132-142, 2002.

[22] B. L. Slomiany and A. Slomiany, "Activation of peroxisome proliferator-activated receptor $\gamma$ impedes Porphyromonas gingivalis lipopolysaccharide interference with salivary mucin synthesis through phosphatidylinositol 3-kinase/ERK pathway," Journal of Physiology and Pharmacology, vol. 54, no. 1, pp. 3-15, 2003. 
[23] B. L. Slomiany and A. Slomiany, "Leptin modulates the detrimental effect of Porphyromonas gingivalis lipopolysaccharideinduced cytosolic phospholipase $\mathrm{A}_{2}$ activation on salivary mucin synthesis via ERK-signal transduction," Inflammopharmacology, vol. 14, no. 5-6, pp. 250-255, 2006.

[24] L. C. Green, D. A. Wagner, J. Glogowski, P. L. Skipper, J. S. Wishnok, and S. R. Tannenbaum, "Analysis of nitrate, nitrite, and $\left[{ }^{15} \mathrm{~N}\right]$ nitrate in biological fluids," Analytical Biochemistry, vol. 126, no. 1, pp. 131-138, 1982.

[25] S. R. Jaffrey, H. Erdjument-Bromage, C. D. Ferris, P. Tempst, and S. H. Snyder, "Protein S-nitrosylation: a physiological signal for neuronal nitric oxide," Nature Cell Biology, vol. 3, no. 2, pp. 193-197, 2001.

[26] M. T. Forrester, M. W. Foster, and J. S. Stamler, "Assessment and application of the biotin switch technique for examining protein S-nitrosylation under conditions of pharmacologically induced oxidative stress," Journal of Biological Chemistry, vol. 282, no. 19, pp. 13977-13983, 2007.

[27] D. Fulton, J. Fontana, G. Sowa et al., "Localization of endothelial nitric-oxide synthase phosphorylated on serine 1179 and nitric oxide in Golgi and plasma membrane defines the existence of two pools of active enzyme," Journal of Biological Chemistry, vol. 277, no. 6, pp. 4277-4284, 2002.

[28] L.A. Ximénez-Fyvie, A. D. Haffajee, and S. S. Socransky, "Microbial composition of supra- and subgingival plaque in subjects with adult periodontitis," Journal of Clinical Periodontology, vol. 27, no. 10, pp. 722-732, 2000.

[29] C. Nonnenmacher, R. Mutters, and L. F. de Jacoby, "Microbiological characteristics of subgingival microbiota in adult periodontitis, localized juvenile periodontitis and rapidly progressive periodontitis subjects," Clinical Microbiology and Infection, vol. 7, no. 4, pp. 213-217, 2001.

[30] B. L. Slomiany and A. Slomiany, "Ghrelin protection against cytotoxic effect of ethanol on rat salivary mucin synthesis involves cytosolic phospholipase $\mathrm{A}_{2}$ activation through snitrosylation," International Journal of Biomedical Science, vol. 6, no. 1, pp. 37-44, 2010. 

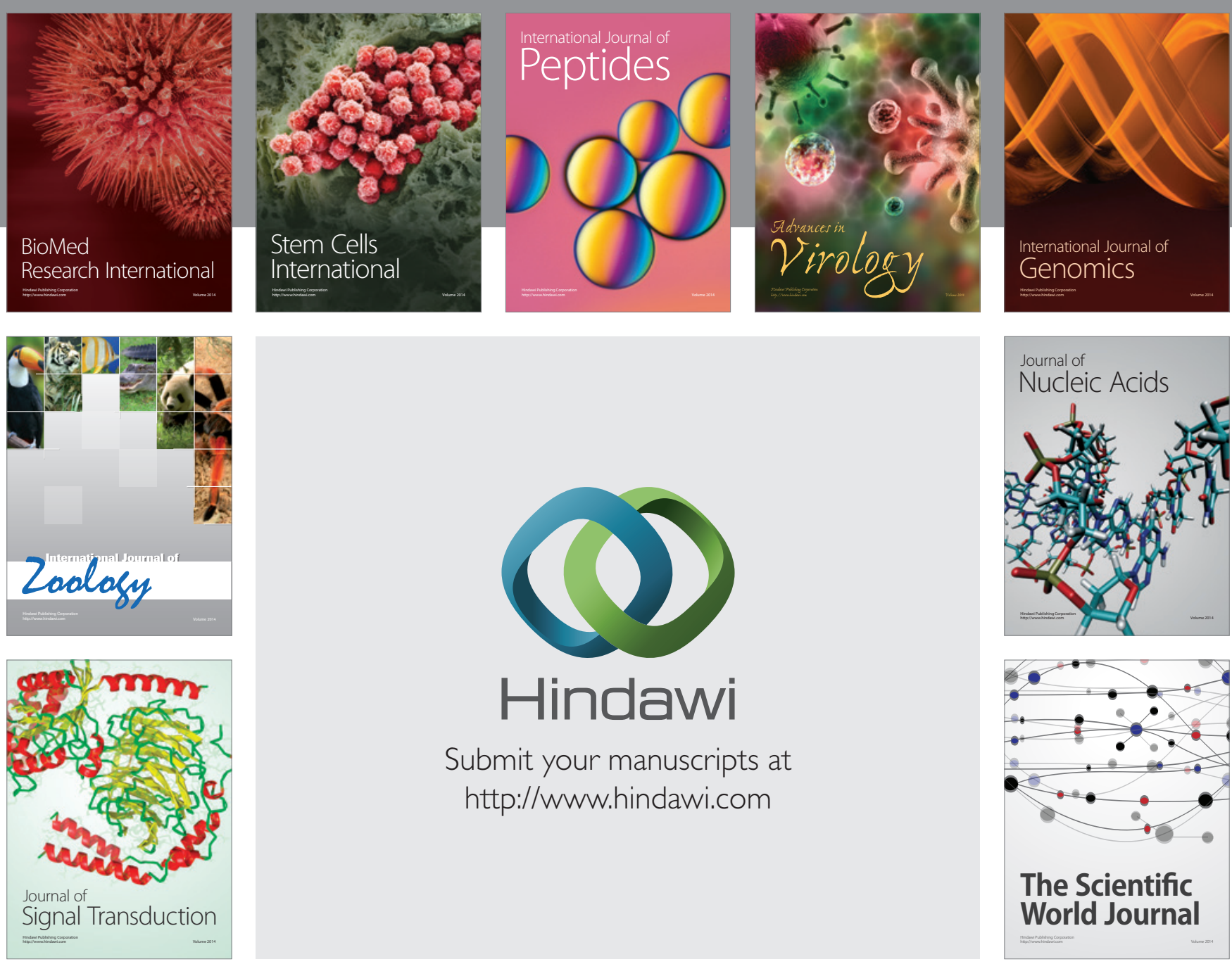

Submit your manuscripts at

http://www.hindawi.com
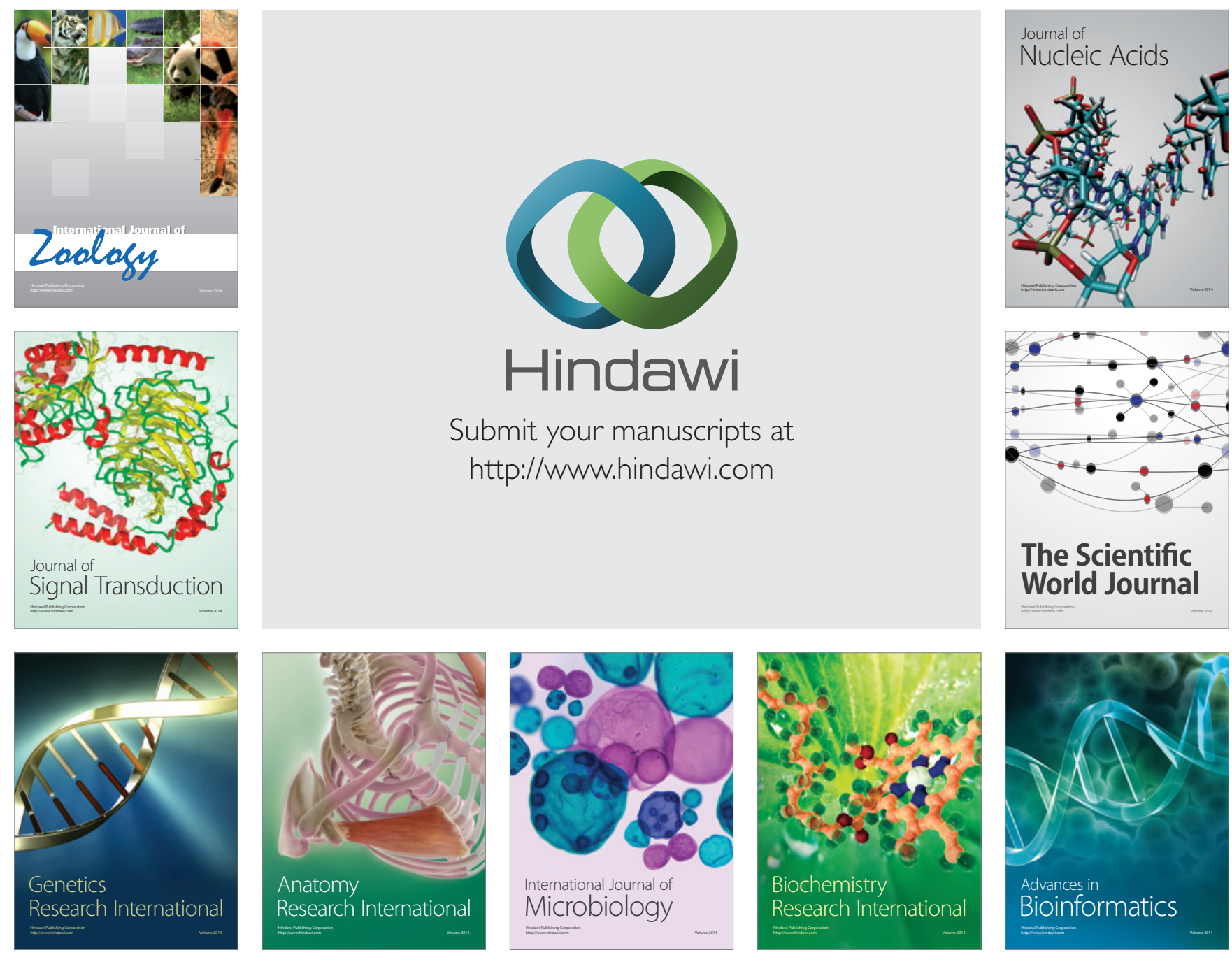

The Scientific World Journal
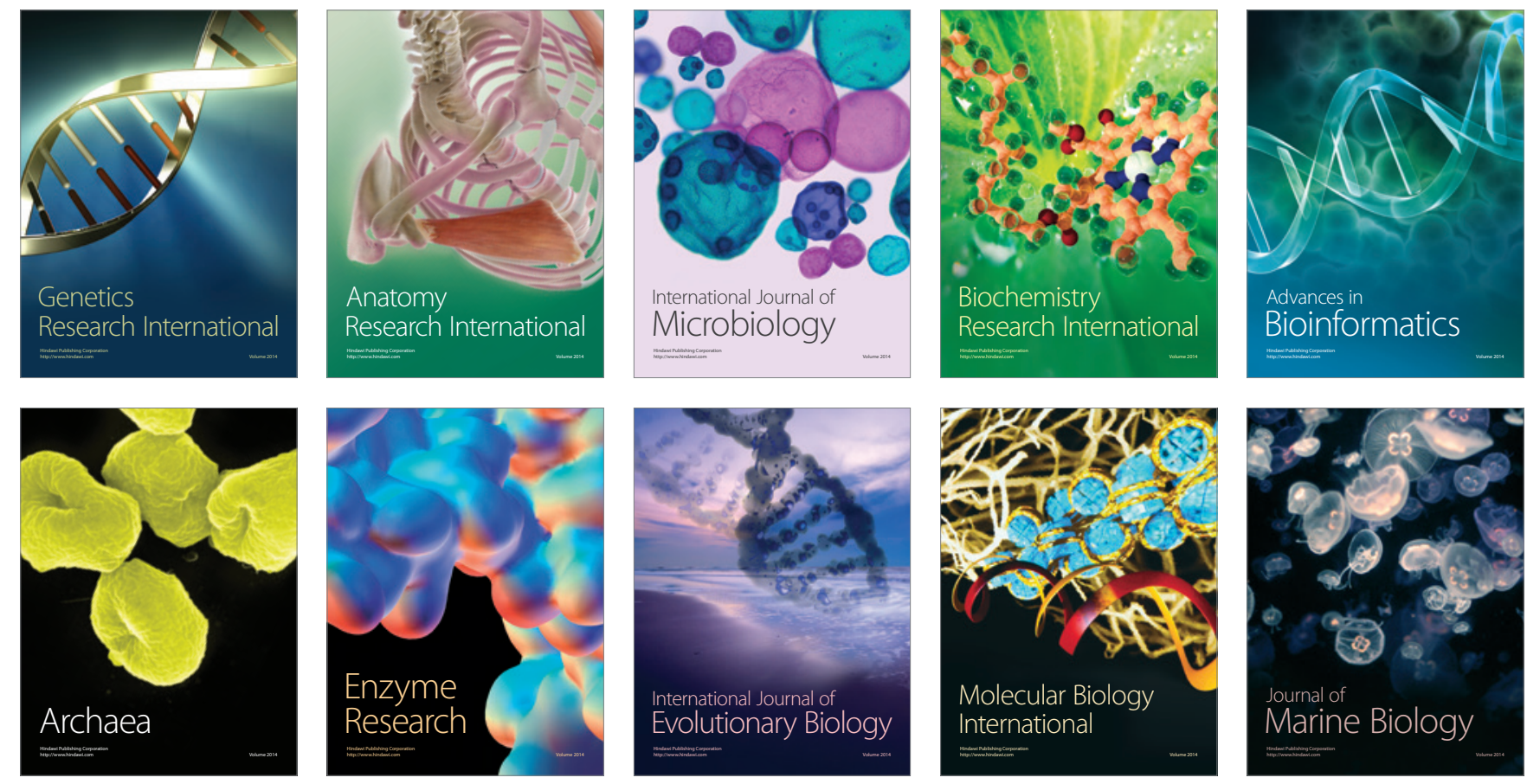